\title{
Evaluating the Outcome of Direct Repair of Bile Duct Injury
}

\author{
AHMED KHALIL, M.D. and KAMAL MAMDOUH, M.D. \\ The Department of Surgery, Faculty of Medicine, Ain Shams University
}

\begin{abstract}
Background: Bile duct injury (BDI) during laparoscopic cholecystectomy is a surgical catastrophe with an incidence ranging. Between 0.3 to $1,4 \%$. Many surgeons think that direct repair of BDI carries a high risk of stricture that is why the bilioenteric reconstruction is more popular.

Aim of Study: Evaluating the results of direct repair in selected cases and compare it to the classic bilioenteric reconstruction.

Methods: We had 2 groups, group A had direct bile duct repair and group B had bilioenteric reconstruction. The choice of doing the direct repair was based on the absence of risk factors for biliary complications. Both are compared as regards the presence of postoperative complications either leakage or stricture and hospital stay. All cases were done in Ain Shams university hospitals during the period between January 2013 until December 2017.
\end{abstract}

Results: Bile leakage had happened in one case of group A (11\%) and 2 cases of group B (16.7\%) with no statistically significant difference, ( $p$-value is 0.72$)$. One case of group A $(11.1 \%)$ had biliary stricture which was presented at 6 months follow up, managed first by ERCP and stent twice and required reconstruction by Roux en Y after 15 months. For group B, 2 cases had anastomotic strictures presented at 9 and 12 months. They were managed by PTC, dilatation, and stenting and followed by redo reconstruction of the anastomosis at 15 and 17 months after the surgery.

Conclusions: Direct repair of the Bile duct can be safely done in properly selected patients with comparable results to bilioenteric reconstruction and no increase in the incidence of postoperative complications.

Key Words: Bile duct injury (BDI) - Direct repair.

\section{Introduction}

BILE duct injury (BDI) during laparoscopic cholecystectomy is a surgical catastrophe with the incidence ranging. Between 0.3 to $1,4 \%$ [1]. The type of repair of the injury is dependant on different factors like the degree and type of injury, time of discovering the injury and the presence of vascular injury. The availability of an experienced hepato-

Correspondence to: Dr. Ahmed Khalil, E-Mail: ahmed abdelrazek@med.asu.edu.eg pancreaticobiliary (HPB) surgeon on call or referral of the patient to a specialized center or HPB unit can improve the outcome of the patient and decrease the long-term complications like secondary biliary cirrhosis. Most cases of BDI that need biliary reconstruction are done by bilioenteric anastomosis. In the era of living donor liver transplant (LDLT) with a duct to duct reconstruction, biliary reconstruction by a duct to duct anastomosis in BDI can be a possible option in properly selected cases. We are evaluating the outcome and comparing the results of 2 groups of bile duct injury, group A with direct repair done and group $B$ who had bilioenteric drainage done. All cases were done in Ain Shams university hospitals during the period between January 2013 until December 2017.

\section{Patients and Methods}

All of the patients had bile duct injury either discovered during surgery with conversion to open with an experienced HPB surgeon was called for the incident or delayed discovery and the patient was referred to our HPB unit.

Statistical analysis was done by using SPSS, $t$ test used for comparison and the $p$-value was calculated to identify the significant variables.

\section{Criteria for direct bile duct repair:}

1- The injury was discovered intraoperatively.

2- No loss of seg ment (the edges of the bile duct can be approximated without any tension).

3- No vascular injury.

4- No excessive cauterization on the bile duct edges.

\section{Criteria for bilioenteric reconstruction:}

1- Delayed presentation with bile leak or sepsis.

2-Presence of vascular injury to the Right hepatic artery. 
3- Excessive cauterization around the edges of the bile duct.

4- Loss of a segment of the bile duct.

\section{Operative technique:}

Upon arrival, adequate assessment of the situation is done with adequate hemostasis and removal of any blindly inserted clips, confirmation that the right hepatic artery was not injured.

The decision to do bilioenteric versus duct to duct reconstruction based on the previous finding that the hepatic artery is not injured plus that the edges of the bile duct are healthy with no excessive cauterization and there is no gap between the 2 edges. Biliary reconstruction was done by interrupted $4 / 0$ or 5/0 PDS and an intra-abdominal drain was inserted.

In case of vascular injury or loss of a segment of the bile duct or excessive burning of the edges, bilioenteric reconstruction was done in the form of Roux en-Y with interrupted 4/0 or 5/0 PDS sutures and an intraopeative drain was inserted.

In case of delayed diagnosis and the patient was transferred to our unit, adequate assessment with MRCP and possible ERCP and CT angiogram on the hepatic vessels to assess the degree of injury and plan the surgical reconstruction. All cases of delayed presentation managed with bilionteric reconstruction.

Cases were compared as regards the postoperative course, hospital stay, postoperative bile leak, late presentation of biliary stricture.

Drains were removed when the drainge is less than 50cc per day, serous in color and no intra abdominal collection by abdominal ultrasound and the liver functions are normal.

\section{Results}

As regards age and sex of the 2 groups, the mean age for group A (direct repair was 40 years and the mean age for the group B (bilioenteric) was 41 years with no statistically significant difference ( $p$-value was 0.83 ).

For group A 3 cases were males and 6 were females and for group B 9 cases were females and 2 cases were males with no statistically significant difference, ( $p$-value was 0.67).
Acute cholecystitis was found only in $33 \%$ of group A cases and $41 \%$ of group B cases there is no statistically significant difference between the 2 groups, ( $p$-value was 0.69 ).

For the type of bile duct injury according to Bismuth Bile duct injury classification, there was no significant difference between the 2 groups. ( $p$ value was 0.82 ) (Table 1).

Table (1): Type of Bile duct injuries.

\begin{tabular}{llllll}
\hline $\begin{array}{l}\text { Type of } \\
\text { bile duct } \\
\text { injury }\end{array}$ & $\begin{array}{c}\text { Direct } \\
\text { repair } \\
\text { group }\end{array}$ & $\begin{array}{c}\text { Bilioenteric } \\
\text { group }\end{array}$ & $\begin{array}{c}\text { Test } \\
\text { value }\end{array}$ & $\begin{array}{c}p- \\
\text { value }\end{array}$ & Sig. \\
\hline \hline D & $1(11.1 \%)$ & $2(16.7 \%)$ & $0.924 *$ & 0.820 & NS \\
E1 & $3(33.3 \%)$ & $3(25.0 \%)$ & & \\
E2 & $4(44.4 \%)$ & $4(33.3 \%)$ & & \\
E3 & $1(11.1 \%)$ & $3(25.0 \%)$ & & \\
\hline
\end{tabular}

The survival was $100 \%$ with no recorded mortality either early postoperative or late after 1 year. Vascular injury was present in $25 \%$ of cases in group B.Bile leakage had happened in one case of group A $(11 \%)$ and 2 cases of group B $(16.7 \%)$ with no statistically significant difference, ( $p$-value is 0.72 ). All the 3 cases were managed conservatively and the bile leakage stopped spontaneously in 5-8 days.

Short and long term follow-up showed that one case from group A $(11.1 \%)$ had biliary stricture which was presented at 6 months follow-up, managed first by ERCP and stenting twice and required reconstruction by Roux en Y after 15 months. For group B, 2 cases had anastomotic strictures presented at 9 and 12 months. They were managed by PTC, dilatation, and stenting and followed by redo reconstruction of the anastomosis at 15 and 17 months after the surgery. No statistically significant difference between the 2 groups.

For hospital stay the median hospital stay for group A was 3 days (most patients were discharged by $\mathrm{PO}$ day 3 ) and the mean was 4.1 days and for group $\mathrm{B}$ the median was 5 days (most patients were discharged by day 5) and the mean was 6 days with statistically significant difference $p$-value $<0.019$.

This can be a reflection of early feeding in cases with direct repair than cases with bilioenteric reconstruction. 


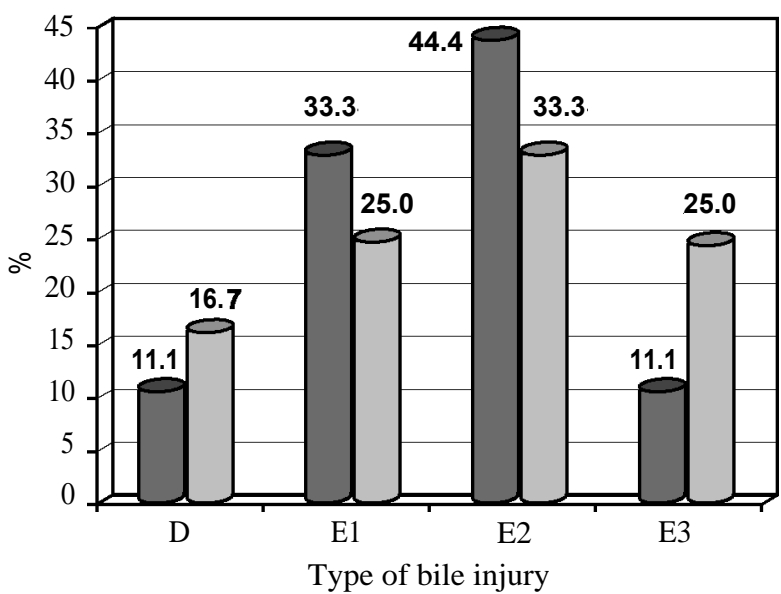

$\square$ Direct repair group $\square$ Bilioenteric group

Fig. (1): Types of Bile duct injury between the 2 groups.

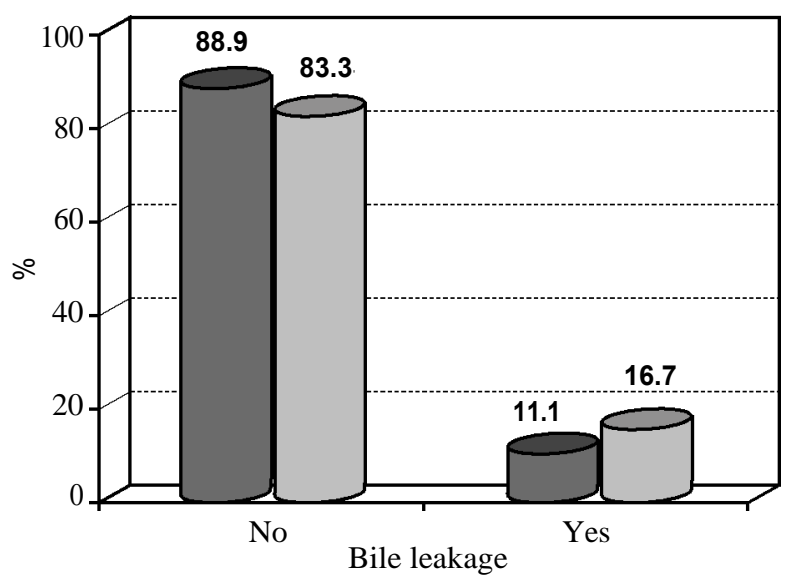

Direct repair group $\square$ Bilioenteric group

Fig. (2): Bile leakage.

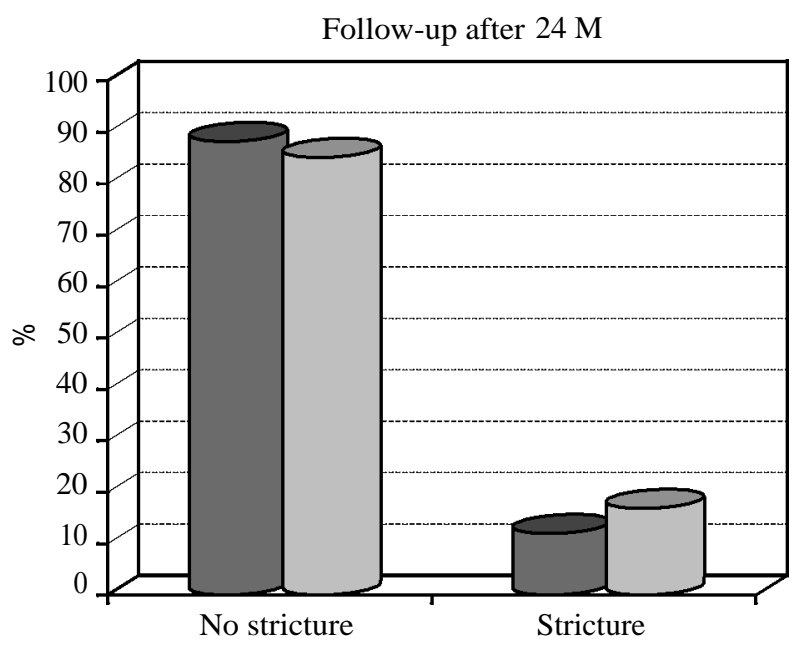

Direct repair group $\square$ Bilioenteric group

Fig. (3): Follow-up after 24 months.

\section{Discussion}

Instead of the decreasing incidence of bile duct injury over the last decade with the lowest rate of major BDI is $0.3 \%$, it is still higher than the rate of BDI during open cholecystectomy which ranges between $0.1-0.2 \%$. [2] and it is a surgical catastrophe with medical, psychological and socioeconomic stress which needs early diagnosis and treatment to avoid serious complications. Sometimes BDI occurs at a higher rate and many cases of BDI are not reported. Yamashita et al., for example, reported from the Japanese national survey data that little change in BDI rates occurred over the past decade, with a mean incidence of $0.66 \%$ [3]

Surgical experience plays an important role in preventing and treating BDI. Schwaitzberg and his colleagues [4] reported that BDI rates are three times more in younger inexperienced surgeons. Also, the availability of an experienced HPB surgeon can improve the outcome after bile duct injury.

Bile duct reconstruction after BDI during laparoscopic cholecystectomy can be in the form of direct repair or bilioenteric reconstruction. Direct repair is not popular for the fear of biliary stricture that is why most surgeons prefer bilioenteric reconstruction. In the era of LDLT with a direct duct to duct reconstruction getting popularity nowadays with a biliary complications rate less than $20 \%$, many surgeons feel comfortable to do direct bile duct reconstruction for BDI after LC in some selected cases.

In our study, we are evalauting the results of Direct bile duct repair by comparing the results of 2 groups of BDI after laparoscopic cholecystectomy. Group A had direct duct repair (9 patients) and group $B$ had Bilioenteric reconstruction (12 patients). Both groups were similar as regards the age, sex and type of bile duct injury with no statistically significant difference between the 2 groups for the previous variables.

Acute cholecystitis was present in up to $38.1 \%$ of the whole cases which may indicate to be a risk factor for BDI. Patrono and his colleagues showed that acute cholecystitis is a nonsignificant trend in cases with BDI and biliary strictures [5]. This can be attributed to the difficulty in identifying the biliary anatomy and also the delay in conversion to open may play another role in BDI.

The one-year survival was $100 \%$ for both groups with no mortality. 
The main cause of biliary stricture is the impairment o the blood supply. The selection of the cases was based on the general principles used in LDLT where excessive dissection of the duct in the donor surgery is avoided to keep the integrity of the duct and the surrounding tissues which provide good blood supply to the duct also any case with vascular injury was excluded from the direct bile duct repair or any duct with loss of long segment which will put the direct repair under tension.

Regarding morbidity, Postoperative bile leak was nearly similar in both groups and had happened in one case from the direct repair group (11.1\%) and 2 cases of the bilioenteric group (16.7\%) with total percentage were $(14.3 \%)$. All were managed conservatively and no statistically significant difference between both groups. Patrono and his colleagues reported similar results of $11.4 \%$ of cases had bile leak after reconstruction.

For postoperative stricture, Sicklick and his colleagues in 2005 reported that half of the patients had direct bile duct reconstruction had 50\% incidence of postoperative stricture [6]. While De Reover and his colleague reported less than $10 \%$ strictures in cases with a direct duct to duct reconstruction [7] with also the advantage of the availability of ERCP and stenting. In our study we reported only one case of biliary stricture in the group A after one year (11.1\%) and needed ERCP and stent followed by conversion to bilioenteric drainage while in the Group B we had 2 cases of stricture in bilioenteric anastomosis (16.6) which needed PTC and dilatation followed by revision. No statistically significant difference between the 2 groups. This means that the incidence of biliary stricture and the stricture in the bilioenteric anastomosis is similar putting in mind that the cases of direct reconstruction are properly selected.

Hospital stay was significantly less with early return to bowel function and tolerance of diet in group A was related to the absence of bowel anastomosis. This, by the way, reduces the hospital coast which can be another advantage of direct reconstruction.

\section{In conclusion:}

Direct bile duct reconstruction for bile duct injury during laparoscopic cholecystectomy in properly selected cases is a safe procedure with no difference in bile leak or stricture rate compared to the bilioenteric reconstruction with the advantage of lower hospital say and lower hospital coast, early feeding and preservation of the bile duct integrity.

\section{References}

1- CONNER'S, et al.: Bile duct injury in the era of laparoscopic cholecystectomy, British Journal of Surgery Society, 93: 153-168, 2006.

2- RYSTEDT J., LINDELL G. and MONTGOMERY A.: Bile duct injuries associated with 55,134 cholecystectomies: Treatment and outcome from a national perspective. World J. Sur., 40: 73-80, 2016.

3- YAMASHITA Y., TAKADA T., STRASBERG S.M., PITT H.A., GOUMA D.J., GARDEN O.J., BUCHLER M.W., GOMI H., DERVENIS C., et al.: TG13 surgical management of acute cholecystitis. J. Hepatol. Biliary. Pancreat. Sci., 20: 89-96, 2013.

4- SCHWAITZBERG S.D., SCOTT D.J., JONES D.B., MCKINLEY S.K., CASTRILLIONJ, HUNTER T.D. and MICHAEL BRUNT L.: Threefold increased bile duct injury rate is associated with less surgeon experience in an insurance claims database: More rigorous training in biliary surgerymay be needed. Surg. Endosc., 28: 30683073, 2014.

5- DAMIANO PATRONO, ROSA BENVENGA, FABIO COLLI, PAOLO BAROFFIO, RENATO ROMAGNOLI, and MAURO SALIZZONI: Surgical management of postcholecystectomy bile duct injuries referral patterns and factors influencing early and long-term outcome: Updates Surg., 67 (3): 2 83-291, DOI: 10.1007/s13304-015-03116, 2015 .

6- J.K. SICKLICK, M.S. CAMP, K.D. LILLEMOE, et al.: "Surgical management of bile duct injuries sustained during laparoscopic cholecystectomy: perioperative results in 200 patients," Annals of Surgery, Vol. 241, No. 5, pp. 786-795, 2005.

7- P.R. de REUVER, O.R.C. BUSCH, E. A. RAUWS, J.S. LAMERIS, T.M. VAN GULIK and D.J. GOUMA:

"Long-term results of a primary end-to-end anastomosis in perioperative detected bile duct injury," Journal of Gastrointestinal Surgery, Vol., 11, No. 3, pp. 296-302, 2007. 


\section{تقييم لعمليات الأصلاح المباشر لأصابة \\ القنوات المرارية}

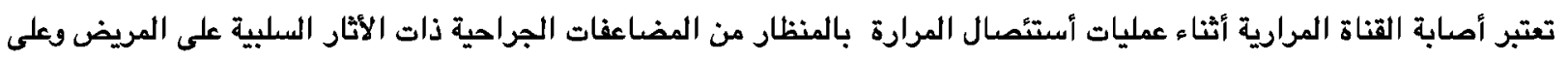

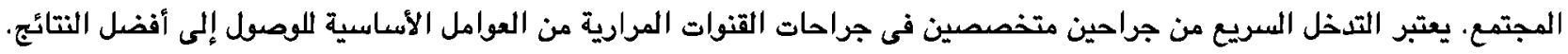
ويقوم هذا البحث بتقييم عمليات الأصلاح المباشر للقناة المرارية من خلال مقارنتها بالأصلاح عن طريق توصيل القناة المرارية بالأمعاء.

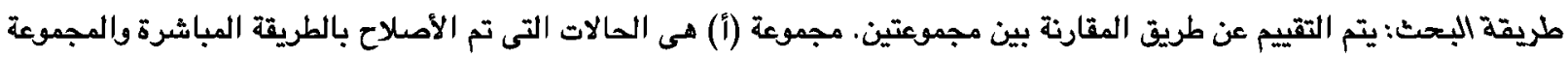

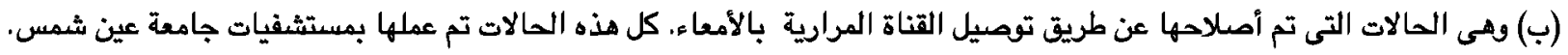

النتائج: حدث تسريب للعصارة الصفراوية فى حالة واحدة من حالات المجموعة (أ) وحالتين من حالات المجموعة (ب) وتم علاجهم بالعلاج

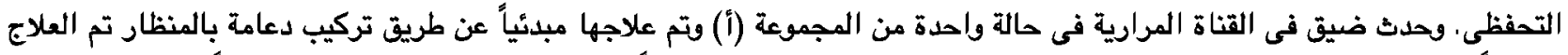
جراحياً. أما بالنسبة المجموعة (ب) فقد حدث ضيق فى حالين وتم أصلاحهم مبدئياً عن طريق الأشعة التداخلية ثم جراحياً. الأستتاج: يعطى الأصلاح المباشر للقناة المرارية نتائج مماثة لأصلاح عن طريق التوصيل بالأمعاء فى حالة الأختيار السليم المريض

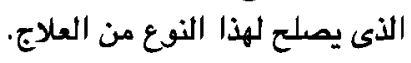

